According to the prison service: 'Prisoners must be categorised objectively according to the likelihood that they will seek to escape and the risk that they would pose should they do so'?

Category A Prisoners whose escape would be highly dangerous to the public or the police or the security of the state and for whom the aim must be to make escape impossible.

Category B Prisoners for whom the very highest conditions of security are not necessary, but for whom escape must be made very difficult.

Category C Prisoners who cannot be trusted in open conditions, but who do not have the resources and will to make a determined escape attempt.

Category D Prisoners who can be reasonably trusted in open conditions.

\section{About the authors}

Nick Kosky is a consultant psychiatrist and medical director, Dorset Community Health Services, Forston Clinic, Dorchester. Clifford Hoyle is an offender mental health development manager, Offender Health South West, Bristol.

\section{References}

1 HM Prison Service \& NHS Executive Working Group. The Future Organisation of Prison Health Care. Department of Health, 1999.

2 Department of Health \& HM Prison Service. Changing the Outlook: A Strategy for Developing Mental Health Services in Prisons. Department of Health, 2001.

3 Royal College of Psychiatrists. Prison Psychiatry: Adult Prisons in England and Wales (College Report CR141). Royal College of Psychiatrists, 2007.

4 Office for National Statistics. Psychiatric Morbidity among Prisoners in England and Wales. ONS, 1997 (http://www.statistics.gov.uk/ STATBASE/Product.asp?vlnk=2676).

5 Department of Health. Improving Health, Supporting Justice: The National Delivery Plan of the Health and Criminal Justice Programme Board. Department of Health, 2009.

6 Daily Hansard. Written Answers 9 January 2007. Hansard, 2007 (http:// www.publications.parliament.uk/pa/cm200607/cmhansrd/cm070109/ text/70109w0018.htm).

7 HM Prison Service. Categorisation and allocation. Prison Service Order no. 0900. HM Prison Service.

\title{
Patients' knowledge about treatment for opiate dependence
}

\author{
Paula Alves, ${ }^{1,2}$ Adam Winstock ${ }^{3}$
}

The Psychiatrist (2011), 35, 448-453, doi: 10.1192/pb.bp.111.034546

\begin{abstract}
${ }^{1}$ European Monitoring Centre for Drugs and Drug Addiction, Portugal: ${ }^{2}$ Centre for Research and Social Intervention, Lisbon University Institute, Portugal; ${ }^{3}$ South London and Maudsley NHS Trust and Institute of Psychiatry, Kings College London, UK

Correspondence to Paula Alves (paulagomesalves@hotmail.com)

First received 11 Mar 2011, final revision 5 Jul 2011, accepted 2 Aug 2011
\end{abstract}

Aims and method A cross-sectional survey was conducted to assess patient knowledge and information provision about opioid substitution treatment among individuals with opiate dependence receiving treatment at four treatment centres in South London.

Results In total 118 people were recruited to the study. Participants answered a mean of 14 out of 34 questions assessing a range of factors such as medication, blood-borne viruses and overdose correctly. Participants overestimated their performance on average by almost $40 \%$. Individuals with a history of previous treatments scored significantly higher than those in their first treatment episode. The majority reported having been given written information on most of the topics assessed.

Clinical implications The results of this study highlight the need to improve education about opioid dependence and its treatment. Poorly informed patients are unlikely to make optimal treatment choices. Improving patients' knowledge and understanding about treatment may lead to better engagement, retention, treatment adherence and, ultimately, better health outcomes.

Declaration of interest None.
Opioid dependence is associated with high rates of psychiatric and physical illness, with significant impacts on the wider community through health costs, crime, blood-borne viruses and family disruption. ${ }^{1,2}$ There are approximately 140000 people on opioid substitution treatment in the UK, with a similar number out of treatment. Buprenorphine and methadone are both evidenced pharmacotherapies that have been consistently 
shown to improve health outcomes and reduce mortality in those with opioid dependence. ${ }^{3,4}$ Being in treatment is associated with significant improvements in health, psychological functioning, as well as reductions in heroin use, other drug use and crime. ${ }^{5-7}$ Longer retention in treatment and higher doses of medication are generally associated with better outcomes. ${ }^{3}$ Unfortunately, retention in treatment for opioid dependence tends to be poor (approximately $50 \%$ at 6 months). ${ }^{8}$

A growing body of evidence now suggests that variables such as the knowledge, beliefs, perceptions and attitudes of opioid users towards opioid pharmacotherapy may influence therapeutic outcomes and early treatment drop out. $^{9-13}$ A recent Australian study of opioid users' knowledge and attitudes about opioid treatment identified significant gaps in knowledge about many aspects of treatment including medication, treatment benefits, risks and perceived side-effects. ${ }^{14}$ These data corroborated previous findings that revealed opioid users' dissatisfaction with the information provided by their doctors regarding medications' pharmacological properties and treatment options. ${ }^{15}$ Research conducted with other psychiatric populations has identified that patients' lack of information about their treatment is not exclusive to the field of substance misuse. British studies carried out with individuals receiving antipsychotic pharmacotherapy showed that the knowledge that they possessed about their medication was insufficient, namely in terms of side-effects. ${ }^{15-17}$ These individuals appeared to be ambivalent towards their treatment and expressed a wish for more information on prescribed medications. ${ }^{15-17}$

Although adherence to and retention in treatment are important modifiers of health outcomes for many chronic conditions, ${ }^{18}$ the potential role of patient education in optimising treatment outcomes has to date received little attention in the field of opioid dependence. In other areas of medicine, however, patient education has been shown to improve treatment adherence and knowledge. ${ }^{15,19}$

Our study aimed to assess the mean knowledge about opioid substitution treatment among patients at treatment centres in South London. Additionally, the level of information provision to these individuals was also estimated, aiming to comprehend to what extent these educational materials/interventions are associated with knowledge about treatment.

\section{Method}

Participants were recruited from four community drug and alcohol teams at South London and the Maudsley National Health Service (NHS) Trust. At the time of recruitment there were, altogether, 1159 people in treatment at these services. To collect data, the researcher attended each of the services for a period of five consecutive days, comprising a study period of approximately 1 month (from 2 November to 4 December 2009). During this period, the researcher approached all patients in the services' common areas (e.g. waiting room, drop-in groups) and offered voluntary entry into the study if they were receiving either methadone or buprenorphine at these units and were over 18 years old.
Overall, a total of 154 patients were approached (13\% of those in treatment at the four services). Of these 154 individuals, 118 (76.3\%) agreed to participate in the study. Ethical approval was received from the joint South London and the Maudsley and Institute of Psychiatry research ethics committee.

This cross-sectional study used a self-report knowledge scale adapted from an instrument developed in Australia. ${ }^{20,21}$ This scale contains 34 true/false items covering four core domains of opioid substitution medications and opioid dependence: knowledge about opioid substitution treatment, overdose, pregnancy and bloodborne viruses (see online supplement to this paper). The knowledge scale used in this study has a good overall internal consistency (Cronbach's $\alpha=0.84$ ), confirming its adequacy for the variables under study. Data regarding demographics, previous and current opioid treatment history and the range/nature of information provision about treatment were also collected.

\section{Statistical analyses}

The primary outcome for this study was the mean knowledge score obtained in the 34-item scale, which represented the arithmetic mean of correct answers provided by each participant. As a secondary outcome, we asked participants the mean number of correct answers they thought they had achieved out of 34. Data analysis was performed using SPSS 17.0 in MS Windows Vista, utilising parametric methods, namely, independent $t$-test (knowledge about treatment in participants receiving methadone and buprenorphine; knowledge about treatment in males and females) and one-way ANOVA (knowledge about treatment and previous treatment experiences). Non-parametric methods (e.g. chi-squared) were also used to compare the differences between participants in both treatment options regarding sociodemographics (e.g. employment status of those receiving methadone $v$. buprenorphine) and treatment variables (e.g. experience of previous treatments in participants receiving methadone $v$. buprenorphine). Linear regression was also performed in order to explore the potential of relevant variables in predicting knowledge about treatment.

\section{Results}

Of 118 participants, 89 (67.8\%) were White British and 96 $(81.6 \%)$ were male. The mean age of the participants was 40.7 years (s.d. $=7.6$, range $24-61)$. Thirty-two $(27.6 \%)$ were unemployed and 65 (56\%) were receiving pension/benefits. Forty-seven (40.2\%) reported not having qualifications.

\section{Treatment characteristics}

In total 101 (85.6\%) participants were receiving treatment with methadone and 17 (14.4\%) with buprenorphine, the majority at community pharmacies under supervision. Seventy-three $(64.4 \%)$ individuals had experience of previous treatment with methadone, buprenorphine or both (Table 1). There were no significant differences 
between demographic and treatment variables across participants prescribed with methadone and buprenorphine.

\section{Overall knowledge about treatment for opioid dependence}

Each correct answer on the 34-item knowledge scale resulted in a score of one point. Out of a maximum score of 34 , the mean knowledge score obtained was 14.74 (s.d. $=4.7$, range 2-25). There was no significant difference in the mean score between those receiving treatment with methadone (14.89) and buprenorphine (13.82, $t=0.84$, $P=0.41)$. Higher knowledge scores were significantly associated with more experience of treatment, with those in the first treatment episode scoring a mean of 13.07 and those with previous treatments with methadone and buprenorphine scoring, on average, $16.25 \quad(F=3.140$, $P=0.03)$. There was also a significant difference between the mean knowledge score in both genders, with the female group more likely to score higher than their male counterparts, respectively $16.59 v .14 .31(t=-2.01, P=0.04)$. At the end of the questionnaire participants were asked to estimate the number of correct answers they thought they had achieved out of 34 . The mean predicted score among participants was 23.12 (s.d. $=6.27$, range $2-34$ ), which represents expectations of obtaining the correct answers to more than $60 \%$ of the items. This compares with an average correct response rate of $43.4 \%$, representing an overestimation of their true knowledge by a mean of $38.2 \%$.

\section{Knowledge about treatment and information provision by topic}

Items in this questionnaire were clustered into six thematic subscales, each representing different topics associated with treatment (Table 2). Most participants (79.7\%) reported being informed about at least one of these topics, with $17.8 \%$ reporting information provision on all the aspects covered by this questionnaire.

\section{Variables potentially associated with knowledge about treatment}

A linear regression analysis was conducted to explore the role of some variables that might predict knowledge about treatment (Table 3). Information provision on the topics 'Overdose' and 'How does medication work' was associated with an increase in knowledge about these topics. Furthermore, those receiving information in one-to-one

\begin{tabular}{lc|}
\hline Table 1 Current and previous treatment history $(n=118)$ \\
& $n(\%)$ \\
\hline Previous treatment episodes & \\
None & $45(35.6)$ \\
With methadone & $46(39)$ \\
With buprenorphine & $7(7.6)$ \\
With methadone and buprenorphine & $20(17.8)$ \\
\hline Current treatment episode, months & \\
$0-5$ & $35(30.4)$ \\
$6-24$ & $28(24.3)$ \\
$25-48$ & $25(21.7)$ \\
$49+$ & $27(23.5)$ \\
\hline
\end{tabular}

sessions with doctors were also more likely to score higher in the knowledge scale.

\section{Discussion}

This study aimed to ascertain knowledge about opioid substitution treatment and relevant areas among patients receiving treatment with methadone and buprenorphine. Despite the majority of participants in this sample reporting receiving information about at least some aspects of treatment, the mean score achieved in this sample suggests significant gaps in knowledge across all core domains of treatment, as in line with previous studies. ${ }^{13,21}$

At the policy level, the importance of patient education in the addictions field has been acknowledged in the UK. Thus, according to the National Institute for Health and Clinical Excellence (NICE) guidelines, ${ }^{22}$ the benefits and risks associated with methadone and buprenorphine should be discussed by the clinician and the patient, so that the latter may participate in the decision-making process. However, the findings from this small study suggest that in spite of current guidelines and the wide provision of information, the current approaches and resources being utilised to inform patients of their condition and its treatment in routine practice across the NHS may be limited in their effectiveness.

Increased knowledge about one's healthcare problems and available treatments can be associated with better clinical outcomes. ${ }^{23-26}$ Although some authors suggest that provision of adequate verbal and written information to motivated patients is advantageous and reinforces adherence, ${ }^{15,23}$ future studies should explore the mechanisms by which improved knowledge about treatment leads to better outcomes and adherence to interventions targeting opioid dependence.

Zaller and colleagues ${ }^{27}$ stress that overlooking education about treatment may lead to undesirable results including increased drug-related morbidity and mortality. ${ }^{28}$ Conversely, recent studies have shown that education can reduce potential harm. For example, research has demonstrated that overdose training increases knowledge about risk factors, preventive strategies and emergency techniques, which could be utilised to avoid preventable deaths. ${ }^{29-31}$ Moreover, as White $e t$ al $^{32}$ recently pointed out, the provision of health-related information is likely to reinforce patient-clinician communication and empower individuals to take a more active role in their treatment decision-making, as advocated by the Royal College of Psychiatrists $^{33}$ and NICE. ${ }^{22}$ Nevertheless, the fact that participants tended to significantly overestimate their knowledge suggests that many may not be in a position to make truly informed decisions regarding their treatment or be aware of the risky nature of their behaviours. If, in addition to poor knowledge, negative attitudes to treatment are also held, these may contribute to drop out.

This study indicates that the source and format of information provision can be important. Despite the existence of potential confounding factors (e.g. inaccurate recalling of events), this study suggests that psychoeducation provided by doctors may be more effective than that provided by other healthcare staff. The explanation for 
Table 2 Mean knowledge by information provision in the respective topic

\begin{tabular}{lcccc} 
Knowledge subscales & $\begin{array}{c}\text { Knowledge score } \\
\text { Mean (s.d.) }\end{array}$ & Range & $\begin{array}{c}\text { Proportion of correct } \\
\text { answers, \% }\end{array}$ & $\begin{array}{c}\text { Patients provided with } \\
\text { information on the topic, \% }\end{array}$ \\
\hline How does medication work & $3.76(1.80)$ & $0-8$ & 47.0 & 76.1 \\
\hline Starting treatment/side-effects & $3.26(1.70)$ & $0-8$ & 40.8 & 55.6 \\
\hline Hepatitis & $3.17(1.51)$ & $0-6$ & 52.8 & 57.3 \\
\hline Overdose & $2.67(1.44)$ & $0-6$ & 44.5 & 56.1 \\
\hline Risks of treatment drop out & $2.07(0.96)$ & $0-3$ & 69.0 & 58.1 \\
\hline Pregnancy and contraception & $1.20(0.97)$ & $0-4$ & 30.0 & 42.4 \\
\hline
\end{tabular}

\begin{tabular}{|c|c|c|c|c|}
\hline & $B(95 \% \mathrm{Cl})$ & s.e. & $t$-test & $P$ \\
\hline \multicolumn{5}{|l|}{ Information provision modality } \\
\hline 1:1 session with key worker & $1.27(-0.78$ to 3.33$)$ & 1.03 & 1.23 & 0.22 \\
\hline 1:1 session with doctor* ${ }^{\star}$ & $2.44(0.52$ to 4.37$)$ & 0.97 & 2.53 & 0.01 \\
\hline Group sessions & $0.57(-1.57$ to 2.72$)$ & 1.08 & 0.53 & 0.59 \\
\hline Leaflets & $-0.29(-2.39$ to 1.81$)$ & 1.06 & -0.28 & 0.78 \\
\hline \multicolumn{5}{|l|}{ Information provision topic } \\
\hline Starting treatment & $1.55(-0.84$ to 3.93$)$ & 1.20 & 1.29 & 0.20 \\
\hline How medication works ${ }^{\star}$ & $-3.42(-5.79$ to -1.04$)$ & 1.19 & -2.86 & 0.01 \\
\hline Side-effects & $-1.44(-3.63$ to 0.76$)$ & 1.10 & -1.30 & 0.19 \\
\hline Risks of treatment drop out & $2.14(0.07$ to 4.35$)$ & 1.11 & 1.92 & 0.06 \\
\hline Contraception & $0.44(-1.48$ to 2.36$)$ & 0.96 & 0.46 & 0.65 \\
\hline Hepatitis & $-2.65(-5.36$ to 0.05$)$ & 1.36 & -1.95 & 0.06 \\
\hline Overdose* & $3.42(0.76$ to 6.08$)$ & 1.34 & 2.56 & $0.01 *$ \\
\hline
\end{tabular}

*Significant at $\alpha=0.05$ level.

this finding is unclear, but it is noteworthy that previous studies have suggested that variables such as staff members' knowledge, attitudes and personal experiences may influence the information they provide to others. ${ }^{34,35}$ Future studies should focus on evaluating the level of knowledge about treatment among staff members, as well as the efficacy of the psychoeducation strategies adopted by different professionals and their perceived credibility by those in treatment. Ultimately, this would inform treatment providers and aid the development of clinical guidelines about the most efficient language, modality and information sources when it comes to increasing individuals' understanding about treatment.

Consideration should also be given as to when information can most effectively be provided. Clinical experience would indicate that written information is usually provided to patients at the start of treatment when patients may have other priorities or may be cycling in and out of withdrawal and intoxication while they stabilise on treatment. Reliance on written information may be misplaced given the low levels of literacy among this population. ${ }^{36}$ That those in their first episode of treatment scored more poorly in this study suggested repeated exposure to information provision may also be important. We suggest that as part of care planning, key workers and prescribers should evaluate the level of knowledge that their patients have about their condition, its treatment and associated risks. This should not be seen as a single event but a continuous process of information exchange and evaluation. Such information exchange may reinforce gains made in treatment and dispel myths about prescribed medications and reduce treatment drop out. ${ }^{37}$

The study is not without limitations. First, the sample size was relatively small, with an uneven number of participants in the methadone and buprenorphine groups. Although this disproportion mirrors what occurs in real circumstances (approximate ratio of 3:1 individuals receiving methadone $v$. buprenorphine), there is the possibility of a type II error when comparing the level of knowledge between the two treatment groups. Similarly, the significant difference in knowledge between males and females might be related to the unevenness of male and female participants, possibly resulting in a type I error. Although the distribution of gender and the split between methadone and buprenorphine is broadly representative of the sample from which the participants were drawn from (E. Finch, personal communication, 2011), we believe strategies to increase sample size (e.g. use of vouchers, larger data collection period) should be considered in future studies to ensure higher statistical power. The questionnaire in this survey has been previously used in a similar study. ${ }^{14}$ Nevertheless, the psychometric properties of this instrument, such as its test-retest reliability or concurrent validity with similar measures, need to be addressed in future validation studies. Another limitation also relates to the questionnaire properties, even though this measure was piloted for its overall understandability, the literacy level of participants in this sample was not determined, hence, it is possible that some participants did not fully comprehend all of the questions. Finally, future research should also focus 
on the resources (e.g. peers, health professionals, media) used by patients to gain knowledge about drug use, its risks and treatment-related areas. Without knowing how information was presented to patients, it is unclear how to develop strategies to improve patients' knowledge and to avoid the perpetuation of myths regarding drug use and its treatment.

\section{Implications}

Opioid users prescribed with methadone and buprenorphine in the UK have low levels of knowledge regarding their condition, the medications used to treat it and related health problems. Increasing knowledge about treatment to improve its effectiveness is likely to be beneficial to both patients and treatment providers. ${ }^{38}$ The combination of overestimation and low levels of knowledge regarding treatment may have significant implications for health outcomes and participation in risky behaviours. Poorly informed patients make less well-informed choices regarding their treatment and this may contribute to a sense of disempowerment, common to many in drug treatment. Information provision should be the responsibility of all clinical staff. Future studies must focus on the development of strategies to improve patients' knowledge, as well as to explore the impact that variables such as beliefs, perceptions and attitudes about treatment may have on the clinical outcomes.

\section{About the authors}

Paula Alves, a psychology graduate, is a research assistant at the European Monitoring Centre of Drugs and Drug Addiction and at the Centre for Research and Social Intervention, Lisbon University Institute, Portugal. Adam Winstock is a consultant psychiatrist at the South London and Maudsley NHS Trust and an honorary senior lecturer at the Institute of Psychiatry, Kings College London, UK.

\section{References}

1 Morrow K, Costello T. HIV, STD and hepatitis prevention among women in methadone maintenance: a qualitative and quantitative needs assessment. AIDS Care 2004; 16: 426-33.

2 Walley AY, White MC, Kushel MB, Song YS, Tulsky JP. Knowledge of and interest in hepatitis $C$ treatment at a methadone clinic. J Subst Abuse Treat 2005; 28: 182-7.

3 Faggiano F, Vigna-Taglianti F, Versino E, Lemma P. Methadone maintenance at different dosages for opioid dependence. Cochrane Database Syst Rev 2003; 3: CD002208.

4 Mattick RP, Kimber J, Breen C, Davoli M. Buprenorphine vs placebo or methadone for opioid dependence. Cochrane Database Syst Rev 2008; 2 CD002207.

5 Darke S, Ross J, Teesson M. Factors associated with 12 months continuous heroin abstinence: findings from the Australian Treatment Outcome Study (ATOS). J Subst Abuse Treat 2005; 28: 255-63.

6 Gossop M, Marsden J, Stewart D, Kidd T. National Treatment Outcome Research Study (NTORS): 4-5 year follow-up results. Addiction 2003: 98: 291-303.

7 Ward J, Mattick RP, Hall W. Methadone Maintenance Treatment \& Opioid Replacement Therapies. Harwood Academic, 1998.

8 Bell J, Burrell T, Indig D, Gilmour S. Cycling in and out of treatment: participation in methadone treatment in NSW, 1990-2002. Drug Alcohol Depend 2006; 81: 55-61.
9 Treloar C, Abelson J, Cao W, Brener L, Kippax S, Schultz L, et al. Barriers and Incentives to Treatment for Illicit Drug Users (Monograph 53). Australian Government Department of Health \& Ageing, National Drug Strategy, 2004.

10 Fischer B, Chin AT, Kuo I, Kirst M, Vlahov D. Canadian illicit opiate users' views on methadone and other opiate prescription treatment: an exploratory qualitative study. Subst Use Misuse 2002; 37: 495-522.

11 Schwartz RP, Kelly SM, O'Grady KE, Mitchell SG, Peterson JA, Reisinger $\mathrm{HS}$, et al. Attitudes toward buprenorphine and methadone among opioid-dependent individuals. Am J Addict 2008; 17: 396-401.

12 Madden A, Lea T, Bath N, Winstock AR. Satisfaction guaranteed? What clients on methadone and buprenorphine think about their treatment. Drug Alcohol Rev 2008; 27: 671-8.

13 Pinto $H$, Rumball D, Holland R. Attitudes and knowledge of substance misusers regarding buprenorphine and methadone maintenance therapy. J Subst Use 2008; 13: 143-53.

14 Winstock AR, Lea T, Maden A, Bath N. Knowledge about buprenorphine and methadone among those receiving treatment for opioid dependence. Drugs Educ Prev Pol 2008; 15: 395-409.

15 Brown CS, Wright RG, Christensen, DB. Association between type of medication instruction and patients' knowledge, side effects and compliance. Hosp Community Psychiatry 1987; 38: 55-60.

16 Haw C, Stubbs J, Calton R, Haynes H. Long-stay psychiatric patients' knowledge and experience in the use of their antipsychotic medication. Hospital Pharmacist 2001; 8: 166-72.

17 Crossley R, Withers P. Antipsychotic medication and people with intellectual disabilities: their knowledge and experiences. J Appl Res Intellect Disabil 2009; 22: 77-86.

18 McLellan AT, Lewis DC, O'Brien CP, Kleber HD. Drug dependence, a chronic medical illness: implications for treatment, insurance and outcomes evaluation. JAMA 2000; 283: 1689-95.

19 Hill J, Bird H, Johnson S. Effect of patient education on adherence to drug treatment for rheumatoid arthritis: a randomised controlled trial. Ann Rheum Dis 2001; 60: 869-75.

20 Winstock AR, Lea T, Fettell A. Pilot evaluation of an educational DVD for people with opioid dependence. Drugs Educ Prev Pol 2009; 16: 18292.

21 Winstock A, Lea T, Maiden A, Bath N. Knowledge about buprenorphine and methadone among those receiving treatment for opiate dependence. Drugs Educ Prev Pol 2008; 15: 395-409.

22 National Institute for Health and Clinical Excellence. Methadone and Buprenorphine for the Management of Opioid Dependence. Department of Health, 2007 (http://www.nice.org.uk/nicemedia/live/11606/33833/ 33833.pdf).

23 Cameron C. Patient compliance: recognition of factors involved and suggestions for promoting compliance with therapeutic regimens. J Adv Nurs 1996; 24: 244-50.

24 Chapman KR, Walker L, Cluley S, Fabbri L. Improving patient compliance with asthma therapy. Respir Med 2000; 94: 2-9.

25 Cochrane GM, Horne R, Chanez P. Compliance in asthma. Respir Med 1999; 93: 763- 9.

26 Lutfey KE, Wishner WJ. Beyond compliance is adherence. Improving the prospect of diabetes care. Diabetes Care 1999; 22: 635-9.

27 Zaller ND, Bazazi AR, Velazquez L, Rich L. Attitudes toward methadone among out-of-treatment minority injection drug users: implications for health disparities. Int J Environ Res Public Health 2009; 6: 787-97.

28 Zanis DA, Woody GE. One-year mortality rates following methadone treatment discharge. Drug Alcohol Depend 1998; 52: 257-60.

29 Dietze $P$, Jolley D, Fry CL, Bammer G, Moore D. When is little knowledge dangerous? Circumstances of recent heroin overdose and links to knowledge of overdose risk factors. Drug Alcohol Depend 2006; 84: 223-30.

30 Worthington N, Piper TM, Galea S, Rosenthal D. Opiate users' knowledge about overdose prevention and naloxone in New York City: a focus group study. Harm Reduct J 2006; 3: 19.

31 Strang J, Manning V, Mayet S, Best D, Titherington E, Santana L, et al. Overdose training and take-home naloxone for opiate users: a 
prospective cohort study of impact on knowledge and attitudes and subsequent management of overdoses. Addiction 2008; 163: 1648-57.

32 White DC, Schelten SL, Kelly BD, Casey P. Written information on bipolar affective disorder: the patients' perspective. Psychiatrist 2010, 34: $418-22$.

33 Royal College of Psychiatrists. About our leaflets. Royal College of Psychiatrists, 2010 (http://www.rcpsych.ac.uk/mentalhealthinfoforall/ moreinformation/aboutourleaflets.aspx).

34 Andrews S, Sorensen JL, Guydish JR, Delucchi K, Greenberg B Knowledge and attitudes about methadone maintenance among staff working in a therapeutic community. J Maint Addict 2005; 3: 47-59.
35 Knudsen HK, Ducharme LJ, Roman PM. Research network involvement and addiction treatment center staff: counsellor attitudes toward buprenorphine. Am J Addict 2007; 16: 365-371.

36 Davis TC, Jackson RH, George RB, Long SW, Talley D, Murphy PW, et al. Reading ability in patients in substance misuse treatment centers. Int $J$ Addict 1993; 28: 571-82.

37 Sokya $M$, Zingg, $C$, Koller G, Kuefner, $H$. Retention rate and substance use in methadone and buprenorphine maintenance therapy and predictors of outcome: results from a randomized study. Int $J$ Neuropsychopharmacol 2008; 11: 641-53.

38 Stancliff S, Myers JE, Steiner S, Drucker E. Beliefs about methadone in an inner-city methadone clinic. J Urban Health 2002; 79: 571-8. 